\title{
Becoming a Xhosa traditional healer: The calling, illness, conflict and belonging
}

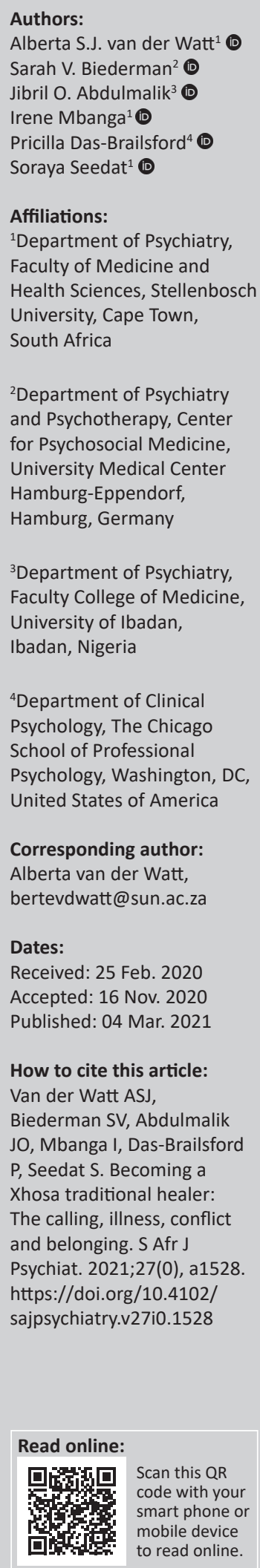

Background: Traditional healers (THs) are an important part of the healthcare system in sub-Saharan Africa. Understanding their training, experiences of becoming healers and their perceived roles in society is critical.

Aim: This study aimed to explore the experience of becoming a $\mathrm{TH}$, including accepting the calling, and sheds light on how the experience is conceptualised within the cultural and communitarian context of THs.

Setting: This study was conducted amongst Xhosa THs in the Western Cape, South Africa.

Methods: In-depth phenomenological interviews $(n=4)$ were conducted with Xhosa THs and analysed using Giorgi's descriptive pre-transcendental Husserlian phenomenological analysis.

Results: The experience of becoming a TH can be summarised in the context of three units of significance: (1) the gift of healing as an illness; (2) the experience of conflict (including with their families, the church and self-conflict); and (3) the experience of belonging. Familial conflict, specifically, was fuelled by the financial burden of becoming a TH and a lack of understanding of the process.

Conclusion: To develop a workable model of collaboration in the future, it is crucial that mental healthcare providers develop a better understanding of the experiences of THs in becoming care providers. The findings highlight an appreciation of the challenging process of becoming a TH. Finally, further research and culturally appropriate psychoeducation can provide trainee THs and their family members with the skills and knowledge to support each other through a difficult process.

Keywords: faith healing; mental health; thwasa; traditional healers; Xhosa.

\section{Introduction}

The widespread use of traditional healers (THs) for the treatment of common mental disorders, especially amongst low-income groups, underscores the importance of exploring their self-identification, training and practices. In sub-Saharan Africa, belief systems that centre on supernatural aetiologies of mental illness are well established. These belief systems include explanatory models alluding to spiritual phenomena, spirit possession and mystical causes..$^{1,2,3}$ These beliefs have implications for help-seeking and utilisation within the formal mental health sector. This has particular relevance for sub-Saharan Africa (comprising low- and middle-income countries) where mental health resources are scarce, the treatment gap approaches $80 \%$, and there is a dire need to improve access to care. ${ }^{4,5}$ More recently, several studies focused on exploring pathways to care for persons with mental illness in sub-Saharan Africa; including the prominence of THs as the first point of contact. ${ }^{6,7,8,9} \mathrm{~A}$ better understanding of THs and their self-perceived roles as providers within their communities is warranted.

Topical areas of research regarding the role of THs in mental healthcare provision include aspects of mental health, such as perceived illness severity, treatment practices and perceived outcomes of persons with mental illness who receive care from THs. ${ }^{10,11,12,13}$ Additionally, the research focuses on knowledge and attitudes of THs towards established signs and symptoms of mental illness, quality of life and their effectiveness as healers. ${ }^{14,15,16}$ In one study, about $60 \%$ of the patients seen by THs met criteria for a diagnosable mental illness, whilst over a third met the criteria for either moderate or severe levels of illness. ${ }^{14}$ Furthermore, a recent quantitative review suggests that THs can provide effective psychosocial interventions by helping to relieve distress and improve mild symptoms in common mental disorders, such as depression and anxiety. ${ }^{15}$ Additionally, a qualitative systematic review found traditional and faith healing for mental illness was perceived as effective. ${ }^{17}$ 
Moreover, some authors explored collaborative partnerships between THs and formal mental health services and have found that these have been met with varying degrees of success. ${ }^{18,19,20,21,22}$ Whilst the controversies, pitfalls and abusive practices (which occur within some $\mathrm{TH}$ settings) are recognised, the potential merits of working partnerships have also been documented and explored. ${ }^{18,19,20,21,22}$ However, whilst a significant proportion of the population affected by mental illness in sub-Saharan Africa continue to seek help and are treated by THs, ${ }^{6,7,8,9}$ a workable model of collaboration between medical health providers and THs remains elusive. ${ }^{18,19,20,21,22}$ A systematic review indicated that a poor understanding between different healthcare providers (such as between physicians and nurse practitioners) of each other's educational training and background was a key barrier to effective collaboration. ${ }^{23}$

\section{Xhosa cultural context in South Africa}

South Africa has approximately 8 million inhabitants of Xhosa descent and the Xhosa language is South Africa's second-most popular official language. ${ }^{24}$ Traditional beliefs are common amongst the Xhosa and use of the traditional healthcare system is a regular and frequent occurrence..$^{25}$ However, the experience of accepting the calling - that is, being called by the ancestors to become a healer - and becoming a Xhosa $\mathrm{TH}$, is not well studied. Literature from the 1970s describes the phenomenon of Thwasa/Intwaso, a state which has been defined as a 'crisis in living ... [and a] creative illness', ${ }^{26}$ as a first step to becoming a Xhosa TH. ${ }^{\mathrm{i}, 30}$ This may present as a period of disintegration where the person no longer perceives him/herself as a whole and experiences some form of communication with his/her ancestors. Dreams and visions are often accompanied by diverse somatic symptoms. These symptoms can appear so extreme that western psychiatrists may interpret them as manifestations of psychotic illness. ${ }^{31}$ However, the Xhosa see this as a gift:

This is the disease of the Igqira which is in me. This type of disease, the thwasa disease, is a gift one receives from one's ancestors, one's grandfathers, whom one does not know but from which one has inherited one's surname. ${ }^{30}$

Such phenomena are described at the beginning of the process of becoming a $\mathrm{TH} .{ }^{32}$ However, besides three studies from the $1970 \mathrm{~s}$ and $1980 \mathrm{~s}^{26,30,31}$ only one recent case description exists on these phenomena in the Xhosa culture. ${ }^{32}$

\section{Theoretical framework}

Social constructionists believe that knowledge is connected to power relations which prescribes what people are allowed to do and know. ${ }^{33}$ Thus, what we know and can do, for example in terms of mental illness, is prescribed by those in power. Feminist social constructionists and post-modern occurs amongst other African ethnic groups, for example, Nguni, ${ }^{27} \mathrm{Zulu}^{28}$ and Sotho ${ }^{29}$ cultures. feminists highlight the way in which knowledge, especially psychiatric knowledge, is derived from a western patriarchal society $^{34}$ which repeatedly asserts power over other societies. As such, knowledge which is different to the dominant construction is often not acknowledged ${ }^{35}$ In much the same way, traditional healing of mental illness is often not acknowledged as valid by proponents of the biomedical paradigm. ${ }^{36,37}$ This lack of acknowledgement pervades despite the evidence suggesting that THs can provide effective psychosocial interventions. ${ }^{15,17}$ In this study, we include the perspectives of the other, the THs, in knowledge making. ${ }^{38}$ Specifically, we use their understanding and experiences of accepting the calling and becoming a $\mathrm{TH}$ to generate knowledge.

\section{Study aims}

To our knowledge, the experience of the calling as an illness has not been explored amongst Xhosa THs in the Western Cape. To develop a workable model of collaboration in the future, it is crucial that mental health care providers develop a better understanding of the experiences of THs in becoming care providers. This study aims to explore the experience of becoming a $\mathrm{TH}$, including accepting the calling, and sheds light on how the experience is conceptualised within the cultural and communitarian ${ }^{\mathrm{ii}}$ context of THs.

\section{Methods Participants}

Four participants (Xhosa-speaking THs, born and raised in South Africa, and practicing as healers in the Western Cape province) were purposefully selected for more focused interviews from a sample of 50 participants $(80 \%=\text { female })^{\mathrm{iii}}$ who participated in a descriptive, quantitative study of the training and practices of THs. ${ }^{39}$ During the aforementioned index study, it became evident that the healers were reluctant to share detailed descriptions of their experiences. We were interested in exploring this further and selected four participants who were willing to participate in this sub-study.

\section{Interviews}

In-depth qualitative interviews, lasting between 54 and 85 minutes, were conducted between July and September 2017 and audio recorded. To assist with the flow of the interviews, the interviewers used an interview schedule containing three open-ended questions: (1) Describe how you knew you had to become a healer; (2) Describe the process and your experience of becoming a healer and (3) Describe the work

ii.Communitarianism is the philosophy that a person's (in this case the TH's) social identity and personality are largely moulded by community relationships, with less development being placed on individualism. This is in line with collectivistic ${ }^{40}$ and Ubuntu culture of the Xhosa people. ${ }^{41}$

iii.Fifty $(N=50)$ IsiXhosa THs, aged 21 and older, born and raised in South Africa and practicing as THs, were purposefully recruited using snowball sampling. Two practicing as THs, were purposefully recruited using snowball sampling. Two from from which participants were recruited, discussed the study with the THs and invited them to participate in the study. Participants were encouraged to refer other interested THs to the study. 
that you do as a healer from the first time a client comes to see you. The questions were specifically broad and open-ended so that the participants had sufficient opportunity to extensively express their view point. ${ }^{42}$

In addition to the interview schedule, interviewers prepared for the interviews by reading through the case files from the index study of these four participants. ${ }^{\text {iv }}$ This provided context for the interviewers and an opportunity for interviewers to prepare any additional, specific questions (e.g. if a participant mentioned a specific dream during the index study they had about becoming a healer, this could be elaborated on in the in-depth qualitative interview). Probing questions were used where more detail and richness were required regarding participants' experience of becoming THs. Thus, we first obtained a description of the experience, followed by probing questions to elicit the meaning and more detail of what was described. ${ }^{43}$

Two interviews were conducted in Xhosa by a clinical psychologist at her office at a government hospital and two interviews were conducted by the first author (a research assistant), in English, at the participants' local church. Xhosa interviews were translated and transcribed by a professional language, translation and copywriting services company. English interviews were transcribed by an MSc student and checked by the first author for accuracy.

\section{Data analysis}

Data were analysed using Giorgi's descriptive pretranscendental Husserlian phenomenological analysis ${ }^{44}$ research method. Phenomenology develops a deeper understanding of subjective human experiences (Rose 1990 as cited in Van der Watt ${ }^{45}$ ) whilst the pre-transcendental Husserlian research aims to scientifically study consciousness. ${ }^{46}$ As a combination, Giorgi's descriptive pre-transcendental Husserlian phenomenological analysis method holds that psychological realities can only be understood through rigorous procedures that are rooted in phenomenological philosophy. ${ }^{47}$ Thus, we processed and analysed individual THs' experiences with the final goal of distilling a psychological experience that is common to all $^{46}$ the participants. This process can be grouped into six steps: (1) grasping a sense of the whole and the context of each interview; (2) extracting units of meaning; (3) clustering of units of meaning to form units of significance; (4) summarising each interview; (5) combining all the interviews into a coherent whole and (6) providing a synopsis of research findings. Through this process, a collective experience of the phenomena ${ }^{44}$ of accepting the calling and becoming a $\mathrm{TH}$ was derived.

\section{Ethical consideration}

Ethical approval was obtained from the Chicago School of Professional Psychology (IRB16-01-0056) and Stellenbosch

iv. This file contained four sections: (1) demographic information; (2) becoming a healer (e.g. when they started training, who trained them, how long they trained, how they knew they had to become healers and so forth; ${ }^{39}(3)$ traditional healing as occupation and (4) client and diagnoses/treatment information.
University (N/16/05/059). Prior to data collection, participants provided informed consent. All files with identifiable information were password protected and kept in a locked office. Participants were reasonably compensated for their time and expenses. ${ }^{65}$

\section{Results and discussion}

Three units of significance emerged from the data: (1) the gift of healing as an illness; (2) the experience of conflict and (3) the experience of belonging. The results (using Xhosa pseudonyms: Nombeko, Nolindo, Nosimo and Ntando) and discussion are presented concurrently.

\section{Case descriptions}

Four female participants consented to the in-depth phenomenological interviews. Male participants were not intentionally excluded. However, the participants in the index study were predominantly female $(80 \%)$ which likely contributed to why all four participants in the current study were female. We present a case description of each participant.

\section{Nombeko (SA-TH01)}

Nombeko (74 years old) is a divorced mother of 10 children. Her highest formal education level is Grade 10. She attends the Methodist church and says her religious orientation did not change when she became a TH. Her paternal grandmother practices as a TH. Nombeko knew she received the calling when she was 17 years old. She started her training at the age of 21 and started to work as a TH when she was 46 years old. Nombeko self-identifies as a traditional doctor and treats mental and physical illnesses. She states that God reveals to her what is wrong with her clients (mode of diagnosis). She mainly uses prayer, herbs and sacrificing animals to treat clients.

\section{Nolindo (SA-TH22)}

Nolindo (67 years old) is a widowed mother of two children. Her highest formal education level is Grade 6. She attends the Old Apostolic church and says her religious orientation did not change when she became a TH. Her grandmother used to practice as a TH but has since passed. Nolindo knew she received the calling when she was 23 years old. She is not sure how old she was when her training started, but she estimates she was around 40 years old. She reckons that she trained for 5 years before she started to work as a TH. Nolindo self-identifies as a sangoma and says she only treats physical illnesses. She states that she 'just knows' what is wrong with a client, or that the ancestors will reveal the diagnosis to her. She mainly uses candles, herbs, incantations and sacrificing animals to treat clients.

\section{Nosimo (SA-TH28)}

Nosimo (45 years old) is a single mother of two children. Her highest formal education level is a diploma in Travelling and Tourism. She used to attend the Anglican Church but changed to the New Apostolic church after she received the calling. Both her parents practice as THs. 
Nosimo knew she received the calling when she was 11 years old. She started her training at the age of 15/16 and started to work as a TH when she was 38 years old. Nosimo self-identifies as a healer and treats mental and physical illnesses. If her ancestors do not reveal to her what is wrong with her client, she uses bones as her primary mode of diagnosis. She mainly uses candles, herbs and sacrificing animals to treat clients.

\section{Ntando (SA-TH33)}

Ntando (45 years old) is a divorced mother of 3 children. She completed a computer course as part of additional skills training. She used to attend both the Seventh Day Adventist and African Gospel churches but changed to the Zionist church after becoming a TH. Her paternal aunt practices as a TH. Ntando knew she received the calling when she was 8 years old. Her parents did not see that she had received the calling, only her grandmother understood. She started her training at the age of 40 and started to work as a TH when she was 41 years old. Ntando selfidentifies as a healer, a sangoma, a herbalist and a spiritualist. She states that she only treats physical illnesses. She uses many modes of diagnosis, including throwing bones, dancing, 'just knowing', revelations from God and her ancestors, as well as signs and symptoms (like a physician). She mainly uses holy water, candles, prayer, herbs, sacrificing animals and hospital medicine ${ }^{\mathrm{v}}$ to treat clients.

\section{The gift of healing as an illness: Receiving and accepting the calling}

Participants described their calling to become healers as a gift: 'everything depends on your gift as a healer' (Nosimo), it is something that 'you are born with' (Ntando), and being a healer is 'natural, it's a gift' (Nolindo). In addition to perceiving the calling as a gift, Nthando experienced her gift as an illness:

'So, I would always tell her [grandmother] my dreams, so she was the one. That is why I said if I got sick at the time, maybe she [grandmother] was still alive then, I would have been a sangoma a long time ago ... there was this uh time that I got sick eh I would uh dream, I would hear the voice of this lady ... then I would just fall asleep ... uh I would be tired it was like uh something was uh draining my body because I was always sleepy, tired like [I] don't have appetite.'

Likewise, Nosimo described experiencing the calling as:

'... I got sick when I was a child. ... I ran away from it but then I got sick ... they [healers] all said the same thing that I have to become a healer.'

She continued to explain how she was:

‘ $[V]$ ery sick as a child I used to have a stomach ache. I used to get very sick and have cramps and even bend. In the long run I suffered from headaches.'

v. Hospital medicine was interpreted as any medication (e.g. Disprin, Panado) which may be prescribed by a medical doctor. Thus, the healer will tell the client to may be prescribed by a medical doctor. Thus, the healer will tell the client to go and
buy Panado, for example. Some would also write a script that the client can take with buy Panado, for example. Some would also write a script that the client can take with
them to the hospital or pharmacy to obtain hospital medication (unpublished data).
Her illness continued to become worse, because:

'I was not even wearing beads. I was still young then and when I wear the beads the other kids will make fun of me, so I decided not to wear them. I became very sick...'

Along the same lines, Nombeko explained how 'they [parents] were forced [to consult a healer] because I was always sick.' Additionally, when describing mental illness, Nombeko explained: '. . . a person may be mental just because [pause] she wants to, he or she wants to be a doctor [pause] like me [softly] ...' thereby linking the calling to become a 'doctor' to mental illness.

However, once a $\mathrm{TH}$ accepted the calling, the illness and symptom manifestations eased. For example, Nolindo explained how she was able to have children after accepting her calling to become a healer:

'But I ignored it [the calling]. ... In my marriage I couldn't bear children. ... And I still couldn't conceive children even after going from this doctor to that one [pause] everywhere seeking help. We were even referred to a doctor in [the suburbs] who was well known for helping people conceive and we still could not get children. ... But we were hopping between them [doctors]... because of desperation we were seeking help everywhere. In that process we opted for traditional healing. ... She [healer] said: "You need to give in to your ancestral calling my child. You're an initiate. Once you undergo the initiation rite everything will go well for you. You will even get what you are struggling to get [pause] that which has brought you to me today" ... The goat was slaughtered for me in October. In November I came back to my husband. And I conceived same time that November on my fifth year in marriage without getting kids.'

Similarly, Ntando said 'there would always be something that is going to bug you all the time until you go straight in whatever the ancestors want.' She continued to explain how things started to improve once she accepted the calling, an improvement which extended to her family:

'... I always ignore $[d]$ that [the calling] ... people would always fight with me, I couldn't get a job, even my husband was fighting with me ... ever since I became a sangoma at home you could see the different [signs], the difference you see because at least now they [family] are able to work, the others they got promotions they [are] buying cars, that never used to happen in my family because when you, when you be[come] a sangoma you heal the family so ja [yes].'

From the above, it is evident that receiving and accepting the calling is experienced individually and that it manifests in a variety of ways, including that of a perceptual phenomenon such as hearing voices. In a western medical paradigm, such phenomena may be considered as a psychotic symptom (e.g. hallucination). However, describing the experience of receiving and accepting the calling to become a $\mathrm{TH}$ as an illness does not take into account the understanding of THs and their experiences. As such, we might postulate that the experience of receiving the calling might be better understood not in terms of an illness, but in terms of a developmental crisis. As part of development, a succession of differentiated phases of 
transitional periods are characterised by cognitive and affective changes which form an integral part of growth. ${ }^{48,49,50}$ This provides opportunities for the development of healthy adaptive reactions. ${ }^{50}$ Accordingly, in the first stage of this process, the calling might be negatively experienced as it alters individual homeostasis, creating the need for a transition. However, as indicated in previous research, ${ }^{51}$ whilst the individual makes this transition, the process of accepting the calling and becoming a healer brings healing. Mlisa (2020) describes this as constructing healing identities that are created and manifested in different socio-cultural, physical and spiritually-abundant sacred spaces travelled by an initiate. ${ }^{52}$ This finding highlights the importance of obtaining a better understanding of the training process of THs. Receiving the calling and answering it is culturally, and often socially, deemed more acceptable than being diagnosed with a mental illness. Indeed, mental illness is often stigmatised in many African cultures. ${ }^{53,54,55}$ It is possible that people with psychiatric symptoms because of mental illness would rather approach THs in the hope that these symptoms are a sign of receiving the calling. Thus, it may be beneficial for biomedical care providers to collaborate with THs to provide them with the necessary resources and knowledge to recognise some trainees with mental illness who could benefit from biomedical treatment.

\section{The experience of conflict}

Participants described becoming a healer as a 'lengthy and tedious passage' (Nolindo) which often resulted in familial conflict and conflict with the church. In turn, this generated self-conflict and confusion.

\section{Familial conflict}

Participants described experiencing conflict with their families for various reasons linked to being, or becoming, THs. For example, Ntando explained how her grandmother was the 'only person who could understand me', whilst the rest of her family 'never wanted anything to do with this thing [the calling] because in their [family] mind they were thinking of their money....' Indeed, as was indicated by participants of the index study, becoming a TH can be a very expensive undertaking, considering the various animals (including chickens, goats and oxen) which must be purchased for specific rituals. ${ }^{39}$ Additionally, it is a lengthy procedure during which time trainees do not receive remuneration. In a country with an unemployment rate of $29.8 \%$, and $41.2 \%$ amongst black women, ${ }^{24}$ it is not surprising that the expensive and lengthy process of becoming a $\mathrm{TH}$ can lead to familial conflict.

In addition to the financial strain, a lack of understanding caused familial conflict. For example, Nosimo explained that her family did not understand her illness and perceived her as simply being 'silly':

'My [biological] mother said, Nosimo is silly now ... It was as if she did not believe me ... my mother also said: "Anyway we did not want her to become a healer" ...She [mother] then looked at me like this and said: "Yoh! I don't know this thing of yours and the amakhosi". ... here at home we are at the St Johns church. So my mom is carrying her cape like she is going to work, and carrying a ladder and going down to a lake as if it is a day for the ceremony and at the same time I am on my knees crying, yho yho! for my mom.'

\section{Similarly, Nombeko said that:}

'[T]hey [family] didn't like me to be, to be, to be a doctor ... and then she [mother] was cross with me, she was cross [laughs] then [laughs] she didn't like it.'

Likewise, Nolindo's mother is quoted as saying: 'No, no, no, I don't have anything to do with traditional things.'

Nosimo explained that her parents 'did not approve me to graduate for red divination because she said she never heard of such healer.' She also acknowledged that their criticism and conflict had some validity:

'It [becoming a healer] is long, because there are other painful difficulties because I became a healer when I was little. I had a hard time graduating, I gave my parents and siblings $[a]$ hard time. I gave my younger sister a hard time, as the result she got sick and lost her job. ... So finally I was at peace with myself because I saw myself as the cause of her not finding any job because she used her money to help me graduate.'

Participants' experiences of the lack of understanding from their families about their situation resonate with the experiences of many individuals with mental illness who feel misunderstood by their families. ${ }^{46,47}$ The excerpts above also suggest that participants wanted their families to understand them and to resolve the conflict. It might be beneficial for family members of $\mathrm{TH}$-trainees to receive culturally appropriate psychoeducation when they exhibit abnormal behaviour, whether this is interpreted as a mental illness, or the receipt of the calling to become a TH. Familial support ${ }^{56,57}$ is important and prolonged familial conflict may have negative consequences. ${ }^{52,53}$ Alleviating the burdens that contribute to familial conflict might be important for improving the quality of life of THs and their families.

\section{Conflict with the church}

Some of the familial conflicts appeared to be related to the church that the family was attending. For example, Nosimo explained:

'We grew up as church goers so my mother does not like healers. So, my mother said I cannot be one [a healer] ... but then they had to do it. So my father went through the course and graduated. When my father graduated my mother disagreed but did not have any choice. ... They made the request to my ancestors not to come strongly...'

Additionally, Nosimo explained that her mother only took her to a healer for treatment because they 'just want [Nosimo] to go back to church.' 
On a related note, Nombeko's mother took her to a church to heal her from her calling:

'... she $[$ mother $]$ took me to, to a certain church people, not Methodists, to, to, to certain church people who, who, who said they can help me and pray [emphasis] for me. ... Pray, so that I may not be [emphasis] ja ... I didn't know if this [the calling] would go away or not, but it didn't.'

When asked why it took her so long to seek help from a healer for her illness and to accept the calling, Ntando simply answered: 'Because I was a church-goer...' However, Ntando, who was very close to her grandmother who was also a $\mathrm{TH}$, had since decided:

‘[B]ecause I loved my grandmother so well now can I call my, because now she's, she's dead can I call her an evil spirit? Can I call her a Satanist or a demon?'

Thus, Ntando appeared to have resolved the initial conflict between becoming a healer and going to church. She indicated that she was working as a healer for God:

'I am doing it [working as a healer] for God [pause] not for people ... because I always know in my heart that I cannot hide anything from God [pause]....because even if the people here [at church] don't see but God can see what I think and what I have done ... I always pray to God [pause]: "You must be the one [emphasis] who anoint me not the people here in church because whatever that I am doing I'm doing it for You." ... if I am in front of the people they mustn't see me they must see the God himself like the spirit it must be all over the church ... now the church people don't like [claps hand on table] me at all.'

Indeed, despite their experienced rejection from the church, participants appeared to continuously integrate worshipping ancestors and God, or working as healers for God. For example, Nosimo explained:

'Because I always beg the ancestors and God so that [pause] I mix them all, that's the way I work, I mix religion and the ancestors because to me they go along together. ... that day [at church] was a ministry day and they did not like the fact that I'm a healer, they were against it. But I told myself I did not come to any of the pastors I'm only here for God. ... I will never get rid of my ancestors, it's either I come to church or I stay home that's it. I love religion, I love going to church ... there is no need for me to struggle if God is with me because he has been there all the time. And $[I]$ also trust my ancestors because they helped me when I was sick and unable to walk, now I'm able to walk because of them.'

Even though she appeared unsure, Nombeko believed the ancestors were sent by God:

'I don't know if I am fooling myself but I think I am not fooling myself telling myself the truth, God, the God will send them [ancestors] sometimes will send my uh, uh, uh ancestors to come and save me.'

From the above, it is clear that the relationship between religious beliefs and traditional beliefs is a complex and conflicting issue for participants, with no simple explanation. In South Africa, belonging to a Christian church does not necessarily imply a break from traditional beliefs, ${ }^{58}$ especially if one is part of an African Independent church. ${ }^{59}$ Indeed, faith healers are embedded within these churches and are seen as 'outstanding persons with clairvoyant and healing powers, operating from within African church[es]. ${ }^{58}$ However, different types of African Independent Churches exist and differ in terms of their following of the 'so-called mainline churches, founded and influenced by missionary colonialism.' ${ }^{60}$ Consequently, some churchgoers, such as the families of participants, may still adhere to colonialist religious views of THs as going against the church's beliefs and dogma, consequently resulting in conflict.

\section{Self-conflict and confusion}

Participants described receiving the calling to become a $\mathrm{TH}$ as sometimes being in conflict with who they are or who they want to be. For example, Nosimo said:

'I never liked to become one [laughing]. ... I don't want to lie, I never liked to become one. It's just I got sick when I was a child. I never woke-up and said I want to be a healer.'

One of the concerns of Nosimo was that becoming a healer conflicted with her identity as a 'lady'; she said: 'I liked to be dressed-up like a lady, so I never liked to become one [a healer].'

Participants described experiencing confusion and not always understanding their calling or the way they were called. For example, Ntando described:

'He [mouse] just came out of my chest and then I was screaming [snaps fingers] then now the words she was saying because she was referring, although that time I couldn't understand, but she was referring to the ancestors.'

Nolindo described her interaction with an elderly lady:

"An [elderly lady] would always say: "Hey, this child is white." And I would cry every time she said that [pause] ... because I was pitch black and I would scratch myself trying to find this place she says was white in me. ... That's when I would cry and scrub myself trying to find the white parts she was talking about because my complexion is black. Not knowing that she was referring to my calling ... And my grandmother said [pause]: "It means you've got ancestral calling or you need to undergo initiation training as a healer." Ancestral calling? Ukuthwasa? I was like: "Eish I do not really understand what that meant." But I ignored it....'

The internal conflict, struggle and confusion experienced by participants were evident. This emphasises the difficulty of receiving the calling and becoming a TH. Previous literature also notes experiences of confusion and sometimes denial when receiving the calling. ${ }^{52}$ This highlights the importance of trainees (and their families) receiving culturally appropriate support throughout the process.

Nosimo's reference to the gender aspect of becoming a TH is interesting, especially if you take into consideration that 
receiving the calling is often deemed a 'woman's gift'. ${ }^{52}$ Indeed, men undergoing the training often use women's dresses even during ritual performances..$^{52}$ Additionally, a study amongst Zulu THs found that female THs have attributes that outclassed their male counterparts ${ }^{61}$ and that female THs are at the pinnacle of the hierarchy of Zulu THs. ${ }^{62}$ Further research is needed to understand gender norms and roles associated with THs, especially amongst the Xhosa population.

\section{The experience of belonging}

Lastly, becoming a TH also meant that participants found a place of belonging. For example, Ntando explained:

'Oh like when I grew up uh I wasn't a, I was a different child to the others, not in the way I was like disabled but I was a different child um people whom they never liked me so much like the other children and even at the home because we have, we were a lot because the aunts and uncles were, everybody was staying at the same house ...so it was difficult because I couldn't get everything that I want like the other children every time if they, they, they buy things for the other children but mine [emphasis] ...they loved me less than the others ... Like now it, I say it was better because I am what I am today because, because at the time I thought they ill-treat me but now I can see they were putting me like for the world ...people are respecting me.'

Becoming a $\mathrm{TH}$ also helped Nolindo to reconnect with her estranged father:

'We then wrote my [estranged] father the letter narrating everything regarding [the calling] ... He replied saying: "You are my firstborn my child and I are [sic] still here for you, come to me." ... I have never met him before.'

Indeed, in some ways, it appeared as if healing brought new recruits into the fold in the form of trainees: 'If I can open my own school ... For my own children [trainees], then I can use my house' (Ntando). Similarly, Nosimo referred to her trainees as children:

'[T] he most important thing that I want in white divination is the fact that I have children of white divination that have to be graduated as healers, and you can never graduate children without being graduated yourself.'

Furthermore, participants referred to their trainers as 'mother'. It is possible that this sense of belonging contributes to the healing effects of $\mathrm{TH}$ training. This sense of belonging can also be linked to the lucrative and respected role in society that THs have. ${ }^{51}$

\section{Limitations}

The present study is not without limitations. Firstly, whilst the sample size is small and limits generalisability, Giorgi cautions that 'research based upon depth strategies should not be confused with research based upon sampling strategies $^{\prime 44}$ and as such does not stipulate the number of participants to be recruited for in-depth phenomenological interviews. However, Giorgi does recommend the inclusion of at least three participants. ${ }^{45}$ Additionally, generalisability was not the main purpose of the present study; rather it was exploratory and based on gaining more insight into what it means to become and to be a Xhosa TH. The goal was to derive formative data that could facilitate a larger future study. Thus, for the purpose of descriptive phenomenological research, the current sample size was deemed adequate. However, future research with a larger sample size is likely to improve the depth, richness and generalisability of the present findings.

Secondly, whilst a professional language, translation and copywriting company translated the Xhosa interviews, the interviews were not back-translated for accuracy because of limited financial resources. Additionally, even though two participants indicated that they were comfortable with conducting the in-depth interviews in English, it was not their first language. This may have influenced participants' ability to accurately describe their feelings and experiences.

Lastly, even though an attempt was made to create a power-neutral interview environment, the powerimbalance between interviewer and interviewee cannot be underestimated. As such, the researchers employed reflexivity in order to avoid prejudice, bias and domination of their own personal ideas, ${ }^{63}$ partly through bracketing. ${ }^{44,64}$ Through bracketing, we brought our own preconceived ideas and perceptions of THs to the foreground to distinguish them from the information provided by the participants. Nonetheless, we recommend that future in-depth interviews be conducted by demographically matched interviewers in a neutral setting.

\section{Conclusion}

This study explored the experience of receiving the calling to become a TH and sheds light on how the experience is conceptualised within the cultural and communitarian context of THs. The current findings highlight the importance of obtaining a better understanding of the training process to become THs. Receiving the calling may manifest as a psychiatric illness, ${ }^{51}$ or it can be understood in terms of a developmental crisis. Accepting the calling and becoming a TH entails conflict; yet it is also a socio-cultural, physical and spiritual journey resulting in a healing identity ${ }^{52}$ and a place to belong. More longitudinal and in-depth phenomenological research is needed to better understand the process from receiving the calling to becoming a skilled $\mathrm{TH}$, especially amongst Xhosa THs. It is important to learn how a TH differentiates between clients that have received the calling versus those who possibly have a mental illness.

It may be beneficial for medical providers to collaborate with THs and their trainees. There is evidence for the importance of familial support ${ }^{5,57}$ and the negative effects of prolonged familial conflict. ${ }^{52,53}$ Alleviating the burdens that contribute to familial conflict might be important for improving the quality of life of THs and their families. This is underscored by the findings of this study and the relevance of culturally appropriate psychoeducation for the 
family members of $\mathrm{TH}$ trainees, and for the $\mathrm{TH}$ trainees themselves. Such culturally appropriate psychoeducation serves the purpose of alleviating both conflict within families, as well as internal struggles and self-conflict experienced by $\mathrm{TH}$ trainees. Such training may also result in improved support from family members to $\mathrm{TH}$ trainees throughout the difficult process of becoming THs. Research is needed on gender norms and the complex relationship between religious and traditional beliefs to develop culturally appropriate psychoeducation programmes.

\section{Acknowledgements}

The authors would like to thank all the participants who took part in the study, as well as M. Sithole for assisting with the interviews.

\section{Competing interests}

All authors declare that they have no conflict of interests relevant to this study.

\section{Authors' contributions}

A.S.J.v.d.W. assisted with designing the study, data collection, data analysis and writing the article. S.V.B. corroborated the data analysis and contributed to writing the article. J.O.A. contributed to writing the article. I.M. assisted with recruitment and contributed to writing the article. P.D.-B. co-conceived the study and contributed to writing the article. S.S. co-conceived the study and contributed to writing the article.

\section{Funding information}

The current research was funded by the South African Research Chair Initiative in Posttraumatic Stress Disorder hosted by Stellenbosch University, funded by the Department of Science and Innovation (DSI) and administered by the National Research Foundation (NRF) (Tier 1 level Research Chair); and by a research grant from The Chicago School of Professional Psychology (Washington DC Campus) funds awarded to Prof. P. Dass-Brailsford.

\section{Data availability statement}

Blinded data may be made available on request.

\section{Disclaimer}

The views expressed in the submitted article are that of the authors and not an official position of the institutions or funders.

\section{References}

1. Sorsdahl K, Flisher A, Wilson Z, Stein D. Explanatory models of mental disorders and treatment practices among traditional healers in Mpumulanga, South Africa. Afr J Psychiatry. 2010;13(4):284-290. https://doi.org/10.4314/ajpsy.v13i4.61878

2. Van Duijl M, Kleijn W, De Jong J. Unravelling the spirits' message: A study of help-seeking steps and explanatory models among patients suffering from spirit possession in Uganda. Int J Ment Health Syst. 2014;8(1):1-13. https://doi. org/10.1186/1752-4458-8-24
3. Hecker T, Barnewitz E, Stenmark H, Iversen V. Pathological spirit possession as a cultural interpretation of trauma-related symptoms. Psychol Trauma. 2016;8(4):468-476. https://doi.org/10.1037/tra0000117

4. Saxena S, Thornicroft G, Knapp M, Whiteford H. Resources for mental health: Scarcity, inequity, and inefficiency. Lancet. 2007;370(9590):878-889. https://doi. org/10.1016/S0140-6736(07)61239-2

5. The WHO World Mental Health Survey Consortium. Prevalence, severity, and unmet need for treatment of mental disorders in the World Health Organization World Mental Health Surveys. JAMA. 2004;291(21):2581-2590. https://doi. org/10.1001/jama.291.21.2581

6. Adewuya A, Makanjuola R. Preferred treatment for mental illness among Southwestern Nigerians. Psychiatr Serv. 2009;60(1):121-124. https://doi. org/10.1176/ps.2009.60.1.121

7. Burns JK, Tomita A. Traditional and religious healers in the pathway to care for people with mental disorders in Africa: A systematic review and meta-analysis. Soc Psychiatry Psychiatr Epidemiol. 2015;50(6):867-877. https://doi.org/10.1007/ s00127-014-0989-7

8. Assad T, Okasha T, Ramy H, et al. Role of traditional healers in the pathway to care of patients with bipolar disorder in Egypt. Int J Soc Psychiatry. 2015;61(6):583-590. https://doi.org/10.1177/0020764014565799

9. Kisa R, Baingana F, Kajungu R, et al. Pathways and access to mental health care services by persons living with severe mental disorders and epilepsy in Uganda, Liberia and Nepal: A qualitative study. BMC Psychiatry. 2016;16(1):1-10. https:// doi.org/10.1186/s12888-016-1008-1

10. Abbo C. Profiles and outcome of traditional healing practices for severe mental illnesses in two districts of Eastern Uganda. Glob Health Action. 2011;4(1):1-15. https://doi.org/10.3402/gha.v4i0.7117

11. Audet CM, Ngobeni S, Graves E, Wagner RG. Mixed methods inquiry into traditional healers' treatment of mental, neurological and substance abus disorders in rural South Africa. PLoS One. 2017;12(12):1-14. https://doi. org/10.1371/journal.pone.0188433

12. Mbwayo AW, Ndetei DM, Mutiso V, Khasakhala LI. Traditional healers and provision of mental health services in cosmopolitan informal settlements in Nairobi, Kenya. Afr J Psychiatry. 2013;16(2):134-140. https://doi.org/10.4314/ ajpsy.v16i2.17

13. Sorketti EA, Zainal NZ, Habil MH. The treatment outcome of psychotic disorders by traditional healers in central Sudan. Int J Soc Psychiatry. 2013;59(4):365-376. https://doi.org/10.1177/0020764012437651

14. Abbo C, Ekblad S, Waako P, Okello E, Musisi S. The prevalence and severity of mental illnesses handled by traditional healers in two districts in Uganda. Afr Health Sci. 2009;9 (Suppl 1):S16-S22.

15. Nortje G, Oladeji B, Gureje O, Seedat S. Effectiveness of traditional healers in treating mental disorders: A systematic review. Lancet Psychiatry. 2016; 3(2):154-170. https://doi.org/10.1016/\$2215-0366(15)00515-5

16. Musyimi CW, Mutiso VN, Nayak SS, Ndetei DM, Henderson DC, Bunders J. Quality of life of depressed and suicidal patients seeking services from traditional and faith healers in rural Kenya. Health Qual Life Outcomes. 2017;15(1):1-10.

17. Van der Watt A, Van de Water T, Nortje G, Oladeji BD, Seedat S, Gureje O. The perceived effectiveness of traditional and faith healing in the treatment of mental illness: A systematic review of qualitative studies. Soc Psychiatry Psychiat Epidemiol. 2018;53(6):555-566. https://doi.org/10.1007/s00127-018-1519-9

18. Campbell-Hall V, Petersen I, Bhana A, Mjadu S, Hosegood V, Flisher AJ. Collaboration between traditional practitioners and primary health care staff in South Africa: Developing a workable partnership for
services. Transcult Psychiatry. 2010;47(4):610-628.

19. Patel V. Traditional healers for mental health care in Africa. Glob Health Action. 2011;4(1):3-4. https://doi.org/10.3402/gha.v4i0.7956

20. Gureje O, Nortje G, Makanjuola V, Oladeji BD, Seedat S, Jenkins R. The role of global traditional and complementary systems of medicine in the treatment of mental health disorders. Lancet Psychiatry. 2015;2(2):168-177. https://doi. org/10.1016/S2215-0366(15)00013-9

21. Keikelame MJ, Swartz L. 'A thing full of stories': TraditionaL healers' explanations of epilepsy and perspectives on collaboration with biomedical health care in Cape Town. Transcult Psychiatry. 2015;52(5):659-680.

22. Musyimi CW, Mutiso VN, Nandoya ES, Ndetei DM. Forming a joint dialogue among faith healers, traditional healers and formal health workers in mental health in a Kenyan setting: Towards common grounds. J Ethnobiol Ethnomed. 2016;12(1):4 https://doi.org/10.1186/s13002-015-0075-6

23. Clarin OA. Strategies to overcome barriers to effective nurse practitioner and physician collaboration. J Nurse Pract. 2007 Sep;3(8):538-548. https://doi. org/10.1016/j.nurpra.2007.05.019

24. Statistics South Africa. Census 2011 - Census in brief [homepage on the Internet] World wide web, 2012; p. 1-102. [cited 2019 Aug 22] Available from: www. statssa.gov.za

25. Schierenbeck I, Johansson P, Andersson LM, Krantz G, Ntaganira J. Collaboration or renunciation? The role of traditional medicine in mental health care in Rwanda and Eastern Cape Province, South Africa. Glob Public Health. 2018:13(2):159-172. https://doi.org/10.1080/17441692.2016.1239269

26. Schweitzer RD, Buhrmann M V. An existential-phenomenological interpretation of Thwasa among the Xhosa. Psychotherapia. 1978;4:15-18.

27. Hammond-Tooke W. Divinatory animals: Further evidence of San/Nguni borrowing? S Afr Archael Bull. 1999;54(170):128-132. https://doi.org/10.2307/3889291

28. Chidester D. Zulu dreamscapes: Senses, media, and authentication in contemporary neo-shamanism. Mater Relig. 2008 Jul;4(2):136-158. https://doi. org/10.2752/175183408X328271 
29. Sodi T. A phenomenological study of healing in a North Sotho community. [Unpublished Doctoral dissertation] University of Cape Town; 1998.

30. Schweitzer RD. Categories of experience amongst the Xhosa: A psychological study. [Unpublished Master's thesis] Rhodes University; 1977.

31. Schweitzer RD. A phenomenological explication of dream interpretation among rural and urban Nguni people. [Unpublished Doctoral dissertation] Rhodes University; 1983.

32. Booi BN, Edwards DJA. Becoming a Xhosa healer: Nomzi's story. Indo-Pac J Phenomenol. 2014;14(2):1-12. https://doi.org/10.2989/IPJP.2014.14.2.3.1242

33. Burr V. Social constructionism. 2nd ed. London: Routledge; 2003.

34. Leavy PL. Feminist postmodernism and poststructuralism. In: Hesse-Biber SN, Leavy PL, editors. Feminist research practice: A primer. Thousand Oaks, CA: Sage, 2007; p. 33-108.

35. Stoppard JM. Understanding depression. London: Routledge; 2000.

36. Ernst E, De Smet PAGM, Shaw D, Murray V. Traditional remedies and the 'test of time'. Eur J Clin Pharmacol. 1998;54(2):99-100.

37. Shaw I, Middleton H. Approaches to 'mental health' in low-income countries: A case study of Uganda. Ment Health Rev J. 2013;18(4):204-213.

38. Baumbusch JL. Unclaimed treasures: Older women's reflections on lifelong singlehood. J Women Aging. 2004 Apr;16(1-2):105-121.

39. Van der Watt ASJ, Das-Brailsford P, Mbanga I, Seedat S. South African isiXhosa traditional healer self-identification, training, practices, and their perceptions of collaboration with medical providers: An exploratory study. South African Journal of Psychology. 2020;50(1):115-127. https://doi.org/10.1177/0081246319856984

40. Eaton L, Louw J. Culture and self in South Africa: Individualism-collectivism predictions. J Soc Psychol. 2000 Apr;140(2):210-217. https://doi.org/10.1080/ 00224540009600461

41. Greeff A. Resilience in Xhosa families [Unpublished Doctoral dissertation] Stellenbosch University; 2006

42. Giorgi A. The theory, practice, and evaluation of phenomenological method as a qualitative research practice procedure. J Phenomenol Psychol. 1997;28(2): 235-260. https://doi.org/10.1163/156916297X00103

43. Bevan MT. A method of phenomenological interviewing. Qual Health Res. 2014;24(1):136-144. https://doi.org/10.1177/1049732313519710

44. Giorgi A. The descriptive phenomenological method in psychology: A modified Husserlian approach. Pittsburgh, PA: Duquesne University Press; 2009.

45. Van der Watt A. Women's experience of being single [Masters]. Stellenbosch: Stellenbosch University; 2015.

46. Finlay L. Engaging phenomenological analysis. Qual Res Psychol. 2014;11(2) 121-141. https://doi.org/10.1080/14780887.2013.807899

47. Eatough V, Smith J. Interpretative phenomenological analysis. In: Willig C, Stayton-Rogers W, editors. The SAGE handbook of qualitative research in psychology interpretative phenomenological analysis. London: Sage, 2008; 193-211

48. Erikson EH. Identity and the life cycle. New York, NY: International American Press, Inc.; 1959.
49. Erikson EH. Identity: Youth and crisis. New York, NY: Norton and Co.; 1968.

50. Eastham K, Coates D, Allodi F. The concept of crisis. Can Psychiatr Assoc J. 1970;15(5):463-472. https://doi.org/10.1177/070674377001500508

51. Van der Zeijst M, Veling W, Makhathini EM, et al. Ancestral calling, traditional health practitioner training and mental illness: An ethnographic study from rural KwaZulu-Natal, South Africa. Transcult Psychiatry. 2020;0(0):1-15. https://doi. org/10.1177/1363461520909615

52. Nomfundo Mlisa LR. I am an igqirha (healer): Phenomenological and experiential spiritual journey towards healing identity construction. Numen. 2020;22(1): 220-239.

53. Egbe CO, Brooke-Sumner C, Kathree T, Selohilwe O, Thornicroft G, Petersen I. Psychiatric stigma and discrimination in South Africa: Perspectives from key stakeholders. BMC Psychiatry. 2014;14(1):191. https://doi.org/10.1186/1471 244X-14-191

54. Amuyunzu-Nyamongo $\mathrm{M}$. The social and cultural aspects of mental health in African societies [homepage on the Internet]. Commonwealth Health

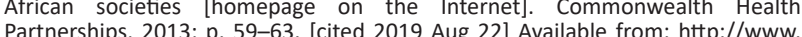
Partnerships, 2013; p. 59-63. [cited 2019 Aug 22] Available from: http://www.
commonwealthhealth.org/wp-content/uploads/2013/07/The-social-andcommonwealthhealth.org/wp-content/uploads/2013/07/Th
cultural-aspects-of-mental-health-in-African-societies_CHP13.pdf

55. Abdullah T, Brown TL. Mental illness stigma and ethnocultural beliefs, values, and norms: An integrative review. Clin Psychol Rev. 2011;31(6):934-948. https://doi. norms: An integrative review.
org/10.1016/j.cpr.2011.05.003

56. Walsh F. Strengthening family resilience. 3rd ed. New York, NY: The Guilford Press; 2016.

57. McCubbin HI, Sussman MB, Patterson JM, editors. Social stress and the family New York, NY: Routledge; 2013.

58. Kahn MS, Kelly KJ. Cultural tensions in psychiatric nursing: Managing the Interface between Western mental health care and Xhosa traditional healing in South Africa. Transcult Psychiatry. 2001;38(1):35-50. https://doi.org/10.1177/1363461 50103800104

59. Gumede MV. Traditional healers: A medical doctor's perspective. Leiden: Blackshaws; 1990.

60. Oosthuizen GC. The healer-prophet in Afro-Christian churches. Leiden: EJ Brill; 1992.

61. Ogana W, Ojong VB. A study of literature on the essence of ubungoma (divination) and conceptions of gender among izangoma (diviners). J Study Relig. 2015;28(1):52-80.

62. Buijs G. The call of the ancestors: Gender identity among Zulu diviners. In: Anthropology Southern African Annual Conference; 31 Oct-2 Nov. Bloemfontein; 2015.

63. Finlay L, Gough B, editors. Reflexivity: A practical guide for researchers in health and social sciences. Oxford: Blackwell Publishing; 2003.

64. Smyth LD. A phenomenological inquiry into the lived experience of social support for Black South African women living with HIV [Unpublished Master thesis] Stellenbosch University; 2004

65. Moodley K, Myer L. Participant remuneration for research - How much is enough? S Afr Med J [serial online]. 2003;93(9):677-678. PMID: 14635555 